\title{
Does the enterolactone (ENL) affect fatty acid transporters and lipid metabolism in liver?
}

\author{
Krzysztof Drygalski", Klaudia Berk, Tomasz Charytoniuk, Nicoletta łowska, Bartłomiej Łukaszuk, \\ Adrian Chabowski and Karolina Konstantynowicz-Nowicka
}

\begin{abstract}
Background: NAFLD as a result of inappropriate diet and obesity, may progress to sever conditions such as: type 2 diabetes mellitus or steatohepatitis, and has recently become a prevalent topic of numerous investigations. Due to its dangerous aftermaths, finding new substances, such as polyphenols and their derivatives, which might reduce liver steatosis is the main target of research into NAFLD treatment. Hence, the aim of the present study was to evaluate the effect(s) of enterolactone (ENL), a metabolite of secoisolariciresinol (SECO), on lipid metabolism together with changes in the expression of fatty acid transporters in fatty liver.
\end{abstract}

Methods: The experiments were conducted on HepG2 cells incubated with either ENL and/or palmitic acid during $16 \mathrm{~h}$ exposure. The expression of selected fatty acid transport proteins: FATP2, FATP5, CD36, FABPpm, ABCA1, MTP, ACBP and L-FABP, as well as the proteins directly involved in lipogenesis (FAS), oxidation pathway (CPT 1), and lipid metabolism (PPARa, LXR, SREBP1C, PAMPK) was estimated by Western Blot. Intra and extracellular lipid contents were assessed by Gas-Liquid Chromatography. The data was analyzed with two-way analysis of variance (ANOVA), and results were considered to be statistically significant at $p \leq 0.05$.

Results: ENL stimulated extracellular efflux of free fatty acids (FFA) and triacylglicerols (TAG) to the medium, while, it had no influence on FATP-family mediated intracellular fatty acid uptake. Moreover, ENL decreased the expression of CPT 1, PAMPK, PPARa, increased SREBP1c and had no effect on LXR, and FAS content.

Conclusions: The findings of our study demonstrate that ENL had opposite effect on liver steatosis in comparison with other polyphenols what suggests that it may be an inactive metabolite. ENL did not affect significantly the intracellular accumulation of FFA, DAG and TAG, yet it promoted their extracellular efflux. Furthermore, it inhibited B-oxydation and intracellular lipid metabolism what may contribute to the progression of NAFLD.

\section{Background}

Non-alcoholic fatty liver disease (NAFLD) is one of the most common, diet related liver diseases appearing especially within societies of developed countries. It is thought that nowadays this pathology may occur in up to $33 \%$ of the general population $[1,2]$. However, the risk of NAFLD may be underestimated due to the still increasing problem of obesity in many western countries, especially among youths [3]. That is why, obesity with accompanying hyperlipidemia, excluding increased alcohol consumption, are the main pathogenetic factors

\footnotetext{
* Correspondence: drygalskikrzysztof@gmail.com

Department of Physiology, Medical University of Bialystok, Białystok, Poland
}

leading to liver steatosis [4]. High fat and high glucose diets result in an elevated free fatty acids (FFA) concentration in plasma, which leads to lipid accumulation in peripheral tissues, including hepatocytes [5]. In NAFLD, the liver accumulates mainly triacylglycerols (TAG), what might be seen in histopathological picture of thick needle biopsy (TNB) as various size cytoplasmatic lipid droplets. Transmembrane FFA uptake is mainly due to the presence of plasma membrane transporters such as: fatty acid translocase (FAT/CD 36), fatty acid transport proteins (FATP2, FATP5) and fatty acid binding protein (FABPpm) [6, 7]. Moreover, intracellular translocation of lipids highly depends on cytosolic liver-type fatty acid binding protein (L-FABP) and acyl binding protein 
(ACBP) which provide high enough concentration gradient for FA diffusion. An excessive intracellular FA flux into hepatocytes is esterified to triacylglycerols (TAG) and/or diacylglycerols (DAG) which may disturb cellular lipid metabolism, leading to the development of steatotic changes [6-8]. Furthermore, long lasting steatosis causes inflammation and progression to non-alcoholic steatohepatitis (NASH) which is a primary risk factor for cirrhosis and hepatocellular carcinoma [9]. Taking into consideration all the above-mentioned aftermath, it is clear that NAFLD is the first step in the development of many diseases caused by a disruption of cell metabolic pathways. As it was shown previously, many polyphenols or phytoestrogens are investigated nowadays as a potential medicine for NAFLD treatment and some of them, such as resveratrol, have reached the level of clinical trials, providing promising outcomes [10]. Based on actual knowledge we have chosen enterolactone (ENL), a phytoestrogen with proven anti-neoplastic and antidiabetic properties for our study [11, 12]. ENL is a natural lignin composed of two phenol rings connected by one lactone ring. It can be found in many plants' seeds such as flaxseed or sesame seed [11, 12]. What is more, ENL might also be synthesized by gut microbiota as a decay product of secoisolariciresinol (SECO) metabolism [13, 14]. Interestingly, the concentration of SECO in patients' plasma is positively correlated with higher plasma HDL and decreased TAG concentration, which information was important in choosing ENL to our research [15]. However, ENL has not been examined before in the context of NAFLD development in connection with fatty acid transporters activity and lipid overload related impairment of the lipid metabolism $[16,15]$.

\section{Methods}

\section{Cell culture}

The experiments were conducted on HepG2/C3A an immortalized human liver cell line, obtained from ATCC (American Type Culture Collection). The cells were maintained on a standard growth medium (DMEM- Dulbecco Modified Eagle Medium) supplemented with $10 \%$ fetal bovine serum (FBS) and 1\% penicillin/streptomycin for 5 days at $37{ }^{\circ} \mathrm{C}$ in a humidified atmosphere containing $5 \%$ of $\mathrm{CO}_{2}$ until they reached $70 \%$ confluency. During this period the cells were rinsed with PBS, and the medium was replaced every $48 \mathrm{~h}$. After 5 days the cells were transferred to 6 well plates and cultured in the growth medium to achieve $90 \%$ of confluence. The morphology and viability of the HepG2 cells were assessed in Bürker chamber using Trypan blue staining.

\section{PA and/or ENL incubation}

Briefly, palmitic acid before administration to the cells was dissolved in a solution of ethanol and $1 \mathrm{M} \mathrm{NaOH}$, heated to $70{ }^{\circ} \mathrm{C}$, mixed with fatty acid-free bovine serum albumin (2\% BSA) and diluted in DMEM [17]. Three hours before performing the experiments cells were serum-starved and next incubated with enterolactone $(50 \mu \mathrm{M})$ alone or combined with palmitic acid $(0.5 \mathrm{mM})$ for $16 \mathrm{~h}$. After this time, HepG2 cells were homogenized in ice-cold radioimmunoprecipitation assay (RIPA) lysis buffer containing protease inhibitors, ultrasonicated and together with postincubation media samples were taken, and frozen in liquid nitrogen. Protein concentration was determined with bicinchonic acid method using BSA as a protein standard.

\section{Immunoblotting analyses}

Routine Western Blotting procedures were used to detect the total expression of fatty acid transport proteins: FATP2, FATP5 (Santa Cruz Biotechnology, USA), FAT/ CD36, FABPpm (Abcam, UK), ABCA1 (Thermo Scientific, USA), MTP (Santa Cruz Biotechnology, USA), ACBP and L-FABP (Abcam, UK) as well as the proteins directly involved in lipogenesis (FAS; Cell Signaling, USA), oxidation pathway (CPT 1; Santa Cruz Biotechnology, USA) and lipid metabolism (PPAR $\alpha$, LXR, SREBP1c, pAMPK; Cell Signaling, USA) as previously described in details by Konstantynowicz-Nowicka et al. [17]. All the antibodies used in our procedures were monoclonal except for FATP2 and FAT/CD36. Cell lysates were separated by $10 \%$ sodium dodecyl sulfate-polyacrylamide gel electrophoresis (SDS-PAGE) and transferred to nitrocellulose membranes. After blocking with $5 \%$ nonfat dry milk, the membranes were immunoblotted with primary antibodies of interest and incubated with secondary antibodies labeled with horseradish peroxidase (HRP). Obtained protein bands were quantified densitometrically using a ChemiDoc visualization system (Bio Rad, Warsaw, Poland). Equal protein loading was controlled by Ponceau $\mathrm{S}$ staining. The expression of all the proteins was standardized to the GAPDH (Santa Cruz Biotechnology, USA) expression and the control was set as $100 \%$.

\section{Intra- and extracellular lipid concentration analyses}

As described previously [7], lipids from HepG2 cells as well as postincubation media were extracted according to the Folch method [18] and separated by thin-layer chromatography (TLC) into fractions of the free fatty acids (FFA), diacylglycerols (DAG) and triacylglycerols (TAG) [19]. Total intra- and extracellular FFA, DAG and TAG contents were assessed as the sum of particular fatty acid species $(14: 0,16: 0,16: 1,17: 0,18: 0,18: 1 \mathrm{n} 9 \mathrm{c}$, 18:2n6c, 20:0, 18:3n3, 22:0, 20:4n6, 24:0, 20:5n3, 24:1, $22: 6 \mathrm{n} 3$ ) of the estimated fractions and expressed in nanomoles per concentration of protein in each sample. 


\section{Data analysis}

The data are expressed as mean values \pm SD based on six independent determinations. Statistical difference between groups was tested two-way analysis of variance (ANOVA), using Statistica 10 (StatSoft, Krakow, Poland). The results were considered to be statistically significant at $P \leq 0.05$.

\section{Results}

\section{Effects of HepG2 cell incubation with PA and/or ENL on} the intracellular FFA, DAG and TAG fraction contents

The exposure of HepG2 cells to PA alone as well as PA combined with ENL induced a considerable intracellular DAG (PA: +32.1\%, ENL + PA: +27.6\%; $\mathbf{P}<0.05)$ and TAG accumulation (PA: $+\mathbf{8 8 . 3} \%$, ENL + PA: +68.2\%; P $<\mathbf{0 . 0 5}$ ) (Fig. 1b, c). Moreover, we revealed that the intracellular FFA concentration in HepG2 cells was significantly elevated only after combined treatment (PA and ENL) as compared to the control group (ENL + PA: +36.8\%; $\mathbf{P}<0.05$ ) (Fig. 1a).

Effects of HepG2 cells incubation with PA and/or ENL on the extracellular FFA, DAG and TAG fraction contents

The incubation of HepG2 cells with PA alone or together with ENL significantly elevated the secretion of FFA into the media as compared with the control group (PA: $+34.8 \%$, ENL + PA: $+\mathbf{4 8 . 6 \%} \boldsymbol{P}<\mathbf{0 . 0 5}$ ) (Fig. 2a). Unexpectedly, we also noticed that DAG concentration in postincubation medium was markedly decreased only in group exposed to ENL combined with PA in comparison to the control group (ENL + PA: $-\mathbf{3 3 . 8 \%} ; \boldsymbol{P}<\mathbf{0 . 0 5}$ )
(Fig. 2b). Similarly to FFA, we revealed a considerable accumulation of extracellular triacylgricerols in the media after PA alone as well as combined with ENL treatment (PA: $+\mathbf{4 1 . 9 \%}$, ENL + PA: $+\mathbf{7 0 . 5 \% , P < 0 . 0 5 )}$ (Fig. 2c). Importantly, ENL alone did not affect FFA and TAG concentrations while its combination with palmitate resulted in a visible additive effect.

Effects of HepG2 cells incubation with PA and/or ENL on total expression of proteins involved in extra- and intracellular lipid transport

Among all the examined proteins involved in fatty acid uptake (FAT/CD36, FATP2, FATP5, FABPpm), we detected a significant increase only in FATP5 expression in PA-treated group exposed to enterolactone (ENL + PA: $\mathbf{+ 1 4 . 6 \% , P}<\mathbf{0 . 0 5}$ ) (Fig. 3). Furthermore, in the case of extracellular lipid transporters there was a considerable rise in ABCA1 expression (ENL: $+\mathbf{2 9 . 6 \%}$, PA: $+\mathbf{3 3 . 6 \%}$, ENL + PA: $+\mathbf{3 8 . 5 \%}, \boldsymbol{P}<\mathbf{0 . 0 5}$ ) (Fig. $4 \mathrm{a}$ ) in all the examined groups compared to the control group, whereas MTP expression increased markedly only in the group incubated with PA alone or combined with ENL (PA: +16.6\%, ENL + PA: +25.3\%, $P<\mathbf{0 . 0 5}$ ) (Fig. 4b).

Effects of HepG2 cells incubation with PA and/or ENL on total expression of cytosolic fatty acid transporters

Total expression of L-FABP was significantly elevated in HepG2 cells exposed to PA alone as well as PA with ENL in comparison to the control group (PA: $+\mathbf{4 0 . 8 \%}$, ENL + PA: $+45.7 \%, P<\mathbf{0 . 0 5}$ ) (Fig. 5a). On the other hand, the expression of ACBP was increased only after
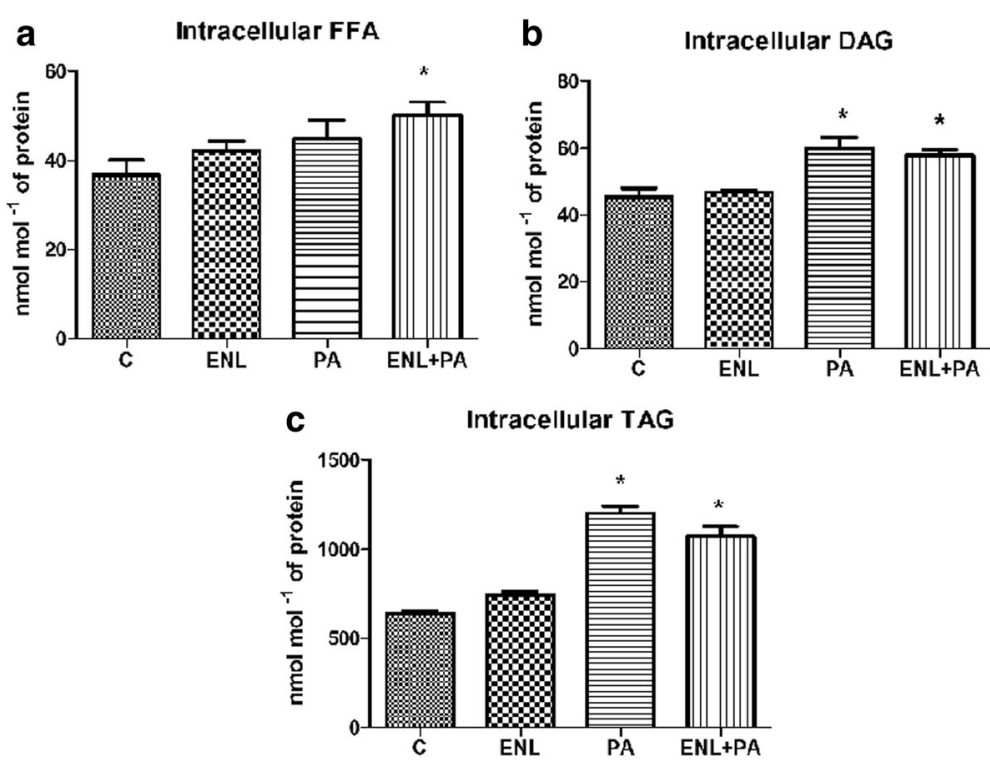

Fig. 1 Intracellular content of free fatty acids (a, diacylglycerols (b) and triacylglycerols (c) in HepG2 cells. The cells were incubated with enterolactone $(50 \mu \mathrm{M})$ alone or combined with palmitic acid $(0.5 \mathrm{mM})$ for $16 \mathrm{~h}$ as it was described in details in Materials and Methods section. Total lipid content was measured by GLC method. The data are expressed as the mean \pm S.D. . ${ }^{*}$ P $<0.05$ significant difference vs control group 


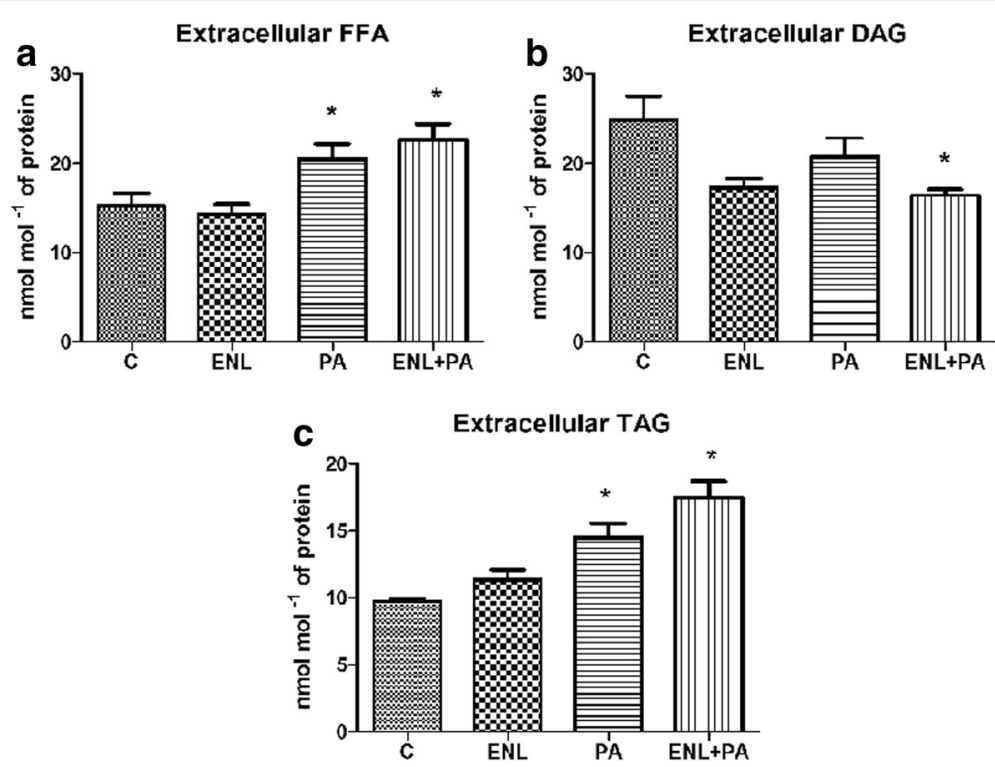

Fig. 2 Extracellular content of free fatty acids (a), diacylglycerols (b) and triacylglycerols (c) in HepG2 cells. The cells were incubated with enterolactone $(50 \mu \mathrm{M})$ alone or combined with palmitic acid $(0.5 \mathrm{mM})$ for $16 \mathrm{~h}$ as it was described in details Materials and Methods section. Total lipid content was measured by GLC method. The data are expressed as the mean \pm S.D. . * P $<0.05$ significant difference vs control group

simultaneous treatment with both palmitic acid and enterolactone (ENL + PA: +30.4\%, P $<$ 0.05) (Fig. 5b).

\section{Effects of HepG2 cells incubation with PA and/or ENL on} total expression of proteins involved in lipogenesis, lipid metabolism and oxidation pathway

In our study we demonstrated that enterolactone has no influence on FAS and LXR (Fig. 6a, c) expression in HepG2 cells. Furthermore, ENL alone or combined with PA decreased significantly PPAR $\alpha$ (ENL: -14.8\%, PA + ENL: $-14.6 \%, P<0.05$ ) (Fig. $6 \mathrm{~b}$ ) and slightly reduced pAMPK (PA: $-21.9 \%$, ENL+ PA: $-14.5 \%$, $P<0.05$ ) (Fig. 6e) expression in comparison to the control group. Moreover, we observed a substantial decline in CPT 1 expression caused by incubation with both PA and PA combined with ENL (PA: -26.3\%, ENL + PA: $-30.6 \%, P<0.05$ ) (Fig. 6f). Interestingly, ENL both alone or combined with PA decreased expression of sterol regulatory element-binding protein (SREBP1c) compared to the control group counteracting PA related activation (ENL: $-23.1 \%$, PA: +45\%, PA + ENL: $-28.7 \%, P<0.05$ ) (Fig. 6d).

\section{Discussion}

One of the main pathological factors of NAFLD development is an increased intracellular TAG content which can be caused by high fat diet administration [4]. It is well known that this change can also be a result of disturbed fatty acids transmembrane transport as well as impaired lipid metabolism in hepatocytes [20]. Both of these processes are possible targets for NAFLD treatment and can be affected by ENL, a flaxseed derived polyphenol [6]. We conducted our experiments on HepG2 cells, being immortalized human liver cell line that still preserve a number of normal liver functions (lipid accumulation, glycogen storage, urea synthesis, phase I and phase II drug metabolizing activities) to assess the influence of ENL treatment in different metabolic conditions (overnutrition) on fatty acid transporters and lipid metabolism. As our study design limitation is not to reflect normally observed in human plasma ENL concentration, based on pilot studies, we considered it to be the most effective [21, 22]. Future studies should be directed at investigating physiological ENL concentration effects or finding new ENL metabolites that are less toxic with the same positive properties. In hepatocytes the transport of fatty acids between extracellular fluid (ECF) and intracellular fluid (ICF) is a result of a few co-existing processes [20,23]. Within them we might distinguish fatty acids uptake facilitated by protein transporters (FAT/CD36, FATP2, FATP5, FABPpm), lipid efflux conducted by ABCA1 and MTP, and concentration gradient-driven diffusion depicted by ACBP, and L-FABP [24, 25]. At present, there are no other investigations reporting the influence of ENL on fatty acid transporters. In our research, ENL supplementation in lipid overload condition did not have any significant influence on FAT/CD 36, FATP2 nor FABPpm transport proteins, a set of transport proteins regulating cellular long chain fatty acids (LCFA) uptake [24, 25]. However, it slightly increased the expression of FATP-5. Probably low expression of the transport proteins in 

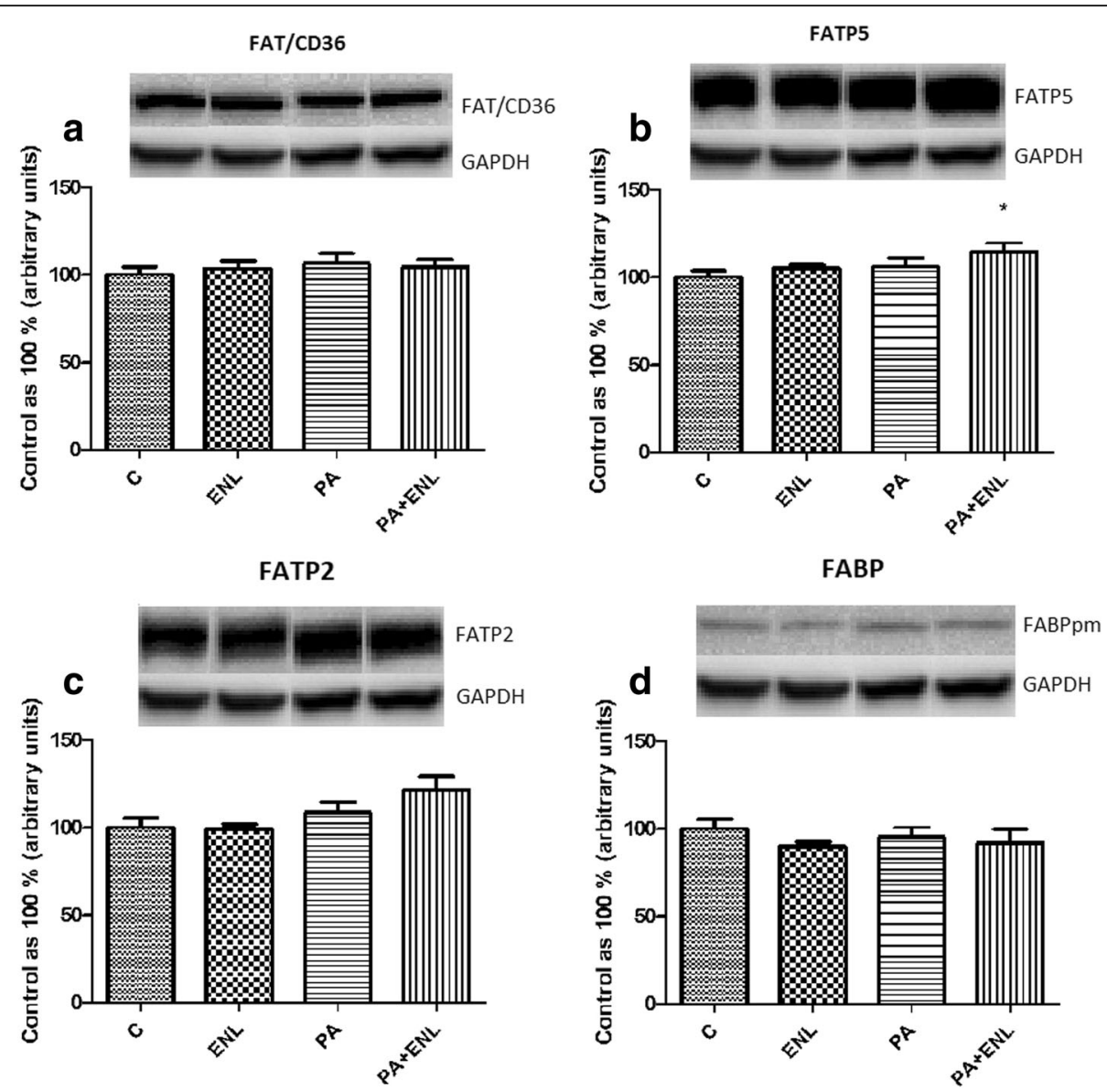

Fig. 3 The expression of proteins involved in plasmalemmal lipid transport i.e. FAT/CD36 (a), FATP5 (b), FATP2 (c), FABPpm (d). The cells were incubated with enterolactone $(50 \mu \mathrm{M})$ alone or combined with palmitic acid $(0.5 \mathrm{mM})$ for $16 \mathrm{~h}$ as it was described in detail in see 'Materials and Methods' section. The protein expression in HepG2 cells was measured using Western blot method. The data are expressed as the mean \pm S.D. * $\mathrm{P}<0.05$ significant difference vs control group

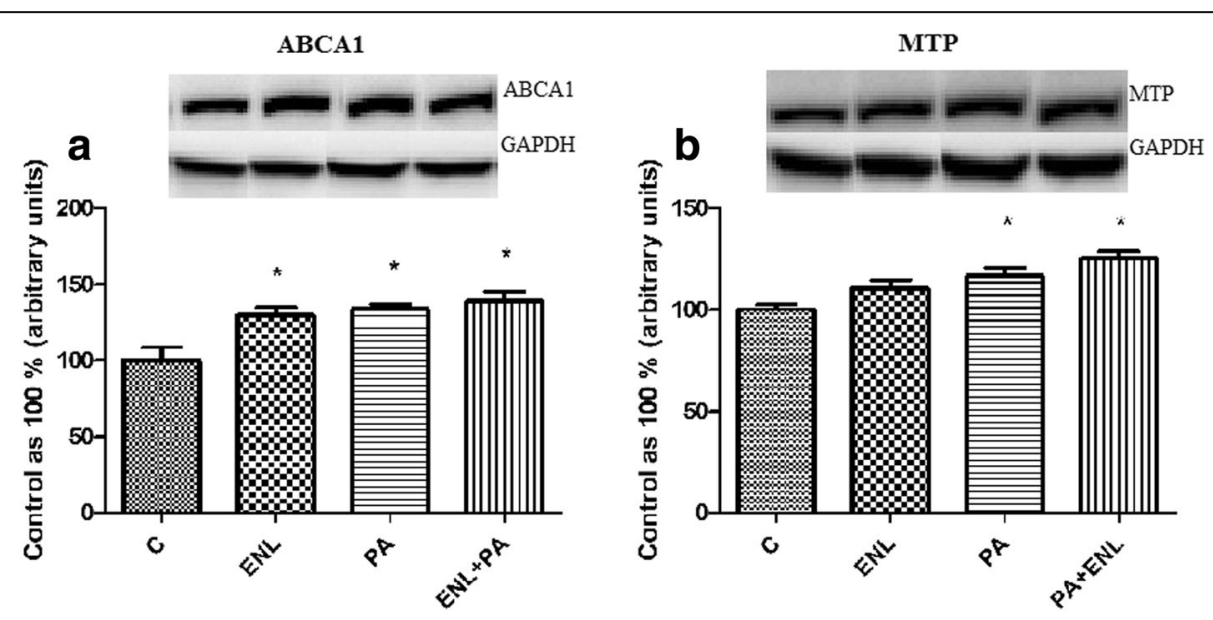

Fig. 4 The expression of proteins involved in extracellular lipid transport i.e. ABCA1 (a), MTP (b). The cells were incubated with enterolactone $(50 \mu \mathrm{M})$ alone or combined with palmitic acid $(0.5 \mathrm{mM})$ for $16 \mathrm{~h}$ as it was described in details Materials and Methods section. The protein expression in HepG2 cells was measured using Western blot method. The data are expressed as the mean \pm S.D. . ${ }^{*} P<0.05$ significant difference vs control group 

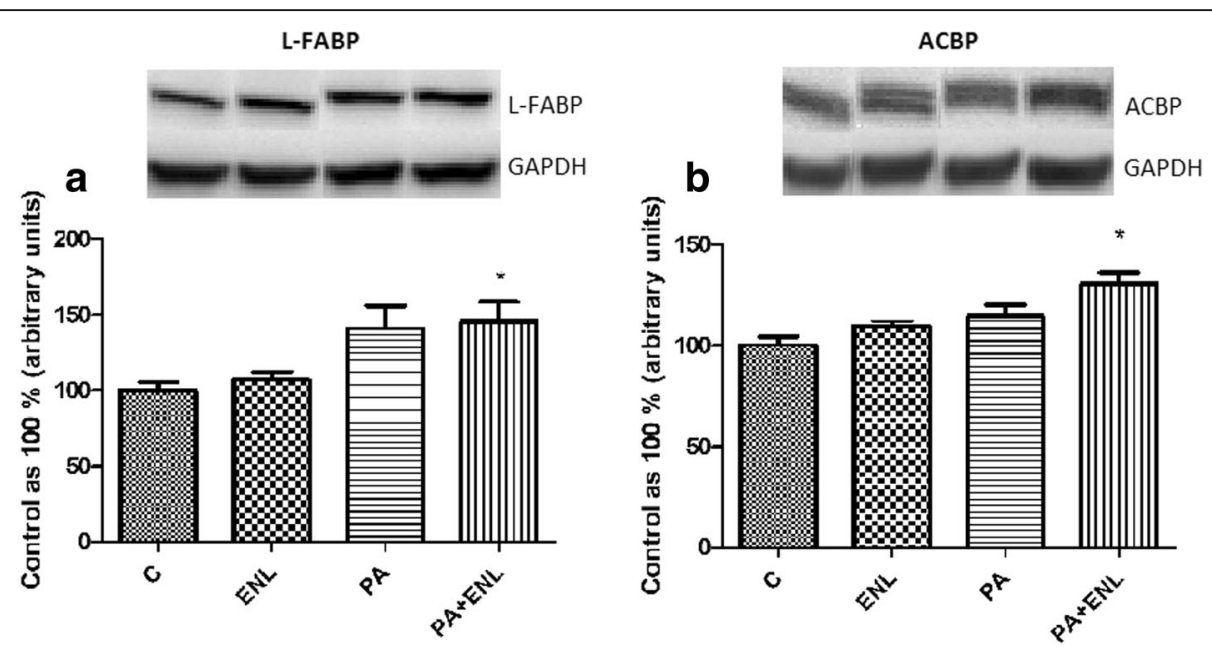

Fig. 5 The expression of cytosolic fatty acids transporters i.e. L-FABP (a), ACBP (b). The cells were incubated with enterolactone $(50 \mu \mathrm{M})$ alone or combined with palmitic acid $(0.5 \mathrm{mM})$ for $16 \mathrm{~h}$ as it was described in details in Materials and Methods section. The protein expression in HepG2 cells was measured using Western blot method. The data are expressed as the mean \pm S.D. ${ }^{*} P<0.05$ significant difference vs control group

HepG2 cells in comparison to primary hepatocytes in general may be a reason why the family of FATP transporters does not play a main role in fatty acid transport in this type of cells [7]. This may suggest that in HepG2 transmembrane transport of fatty acids is mainly a result of high intracellular diffusion gradient via L-FABP rather than mediated by protein transporters because changes observed in their expression were quite small. We only observed significant changes in FATP-5 expression which, at this condition, may be sufficient enough to increase FA influx. Moreover, it appears that this effect may be associated with observed simultaneously decreased expression of PAMPK and PPAR $\alpha$, which are activators of lipids uptake via fatty acid transporters such as: FAT/CD36, FATP-2 or FATP-5 $[26,27]$. What is more, ENL supplementation stimulated ACBP and LFABP mediated long and medium-chain fatty acids (LCFA, MCFA) binding and their transport between organelles and outside the cells, protecting hepatocytes from oxidative damage and cytotoxicity of free fatty acids [28]. However, significantly increased L-FABP expression is not correlated with PPAR $\alpha$ changes what is surprising since peroxisome proliferator acivated receptor stimulates its activity. We suspect that it may be other than PPAR alpha activating mechanisms, especially in HepG2 cells, or excessive lipid availability directly increased the expression of this transporter. The second type of transport (diffusion) was correlated with increased expression of ABCA1 and MTP, suggesting ENL related intensification of fatty acid efflux [29]. ABCA1 which is a transmembrane LXR controlled regulatory protein, together with MTP, another transmembrane extracellular transporter, are crucial for cholesterol and phospholipids efflux and thus necessary for synthesis of
HDL, and ApoB lipoprotein [30, 31]. Our study showed that ENL combined with PA increased the efflux of FFA and TAG to the media, decreasing extracellular DAG concentration at the same time. Both ABCA1 and MTP regulate ECF lipid profile, ejecting excess of fatty acids outside the hepatocytes $[23,30]$. Nevertheless, a bit different effects of ENL were observed in an animal model. In line with this study also other authors shown that SECO and its metabolites such as enterodiol (END) and ENL in vivo decreased expression of SREBP1c [32]. However, above substances have also increased the expression of PPAR $\alpha$, acyl-CoA oxidase (ACOX) and CPT 1 genes what have not been observed in our investigation [32]. Furthermore, supplementation of abovementioned polyphenols resulted in a decreased body weight gain via increased secretion of leptin what might explain their beneficial role in liver steatosis and obesity in animals [32, 33]. Nevertheless, in our experiment no significant changes have been observed in lipid fractions concentration as a result of only ENL supplementation. On the other hand, when we consider intracellular lipid content, ENL mixed with PA significantly increased FFA concentration, similarly to extracellular fluid (ECF). Moreover, ENL combined with PA slightly reduced the PA evoked augmentation of DAG and TAG compared to ENL alone. Furthermore, simultaneous elevation of TAG concentration in examined media may suggest that the addition of ENL promotes its transport outside the hepatocytes, which might be beneficial, protecting the liver from lipid overload. What is more, ENL significantly reduced carnitine palmitoyltransferase 1 (CPT 1) expression, which is responsible for mitochondrial fatty acid transport, and thus lipid oxidation in hepatocytes [34]. In contrast to our results, Tominaga in vivo study 

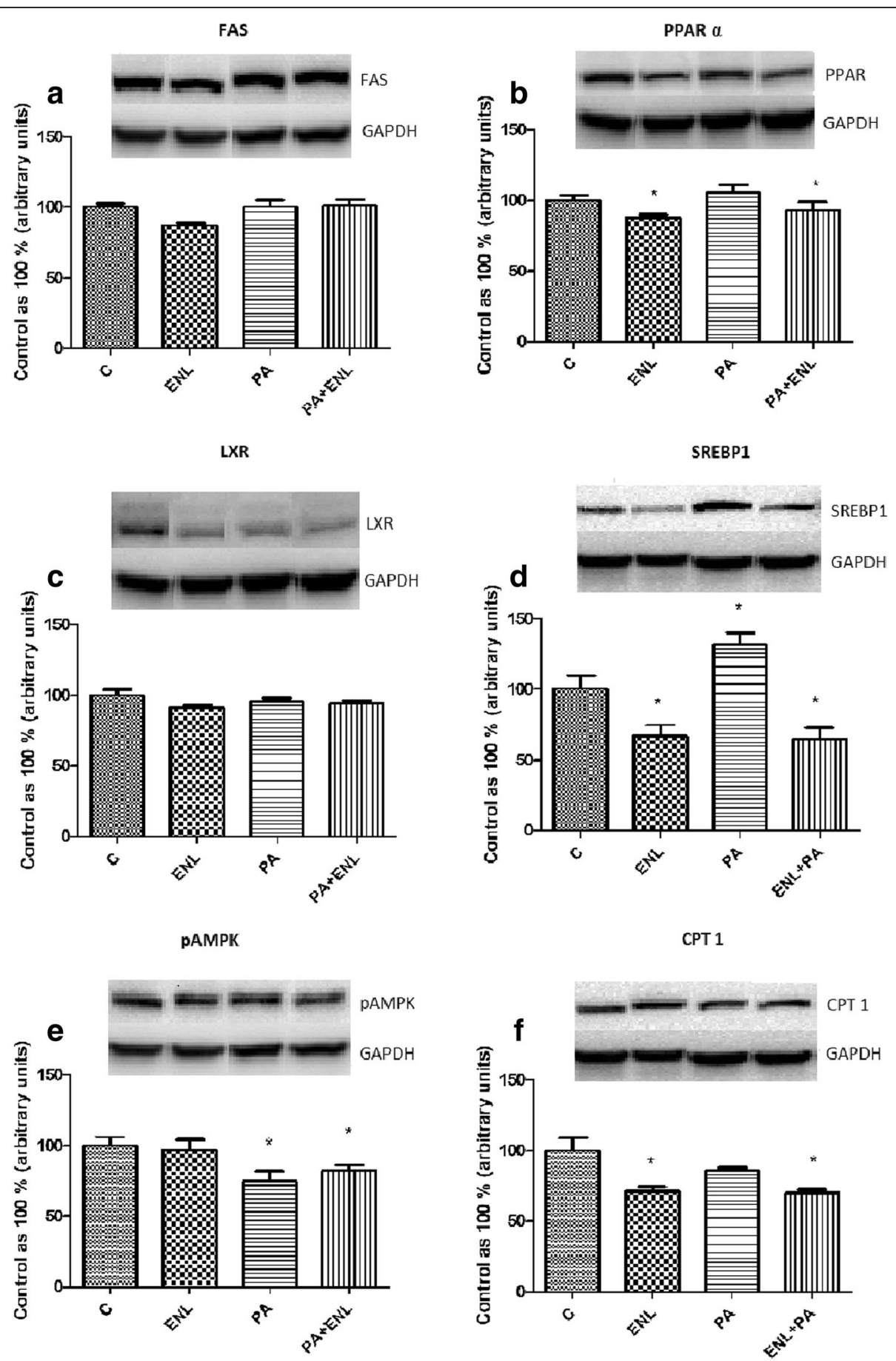

Fig. 6 The expression of proteins involved in lipogenesis i.e. FAS (a), lipid metabolism i.e. PPARa (b), LXR (c), SREBP1c (d), PAMPK (e) and oxidation pathway i.e. CPT 1 (f). The cells were incubated with enterolactone $(50 \mu \mathrm{M})$ alone or combined with palmitic acid $(0.5 \mathrm{mM})$ for $16 \mathrm{~h}$ as it was described in details in Materials and Methods section. The protein expression in HepG2 cells was measured using Western blot method. The data are expressed as the mean \pm S.D. ${ }^{*} P<0.05$ significant difference vs control group

showed no effect of low ENL dosage on CPT 1 genes expression and its stimulation in high ones [32]. We can suspect that this discrepancy was caused by different doses of ENL, which in the case of our research was high enough to trigger changes in protein expression.
Nevertheless, when we consider our experiment, the reduction in CPT 1 expression was correlated with a decreased expression of pAMPK, a protein junction point between lipid oxidation and de novo synthesis pathway $[35,36]$. Decrease of AMPK stimulated TAG and FFA 
synthesis in PA and ENL + PA groups and inhibited lipid oxidation. These findings suggest that, inhibited fatty acids delivery to mitochondria and thus impaired oxidation resulted in an excessive lipid accumulation [37]. Furthermore, ENL both alone and combined with PA significantly reduced PPAR $\alpha$ expression contributing to inhibited fatty acids oxidation, decreased fatty acids uptake, and probably declined CPT 1 expression. It is widely known that PPAR $\alpha$ regulates not only lipids but also carbohydrates metabolism in hepatocytes [38]. Studies conducted by many researchers have shown that lower PPAR $\alpha$ expression favors hepatic glucose production and is also correlated with insulin resistance, causing deterioration of NAFLD [39-41]. However, Pan et al. did not notice significant changes in insulin sensivity after supplementation with flaxseed-derived lignans in type 2 diabetic patients [42]. As far as lipid metabolism is concerned, our observations also indicate that ENL would likely have an influence on fatty acid de novo synthesis pathway by decreasing the expression of SREBP1c what might suggest antisteatotic effect of ENL in the incubated cells. Surprisingly, this result did not correlate with significant changes neither in liver $\mathrm{X}$ receptor (LXR), nor FAS expression what have been frequently observed in NAFLD patients [38, 43]. We can suspect that this discrepancy may be either a result of selective influence of ENL on FAS and SREBP1c or increased transmembrane transport was sufficient enough to cause TAG, DAG accumulation, especially when FA oxidation remained not changed. According to our results, ENL had a opposite effect on lipid transport and metabolism in comparison to its main source product SECO and other commonly examined lignans such as: resveratrol (RSV), kukoamine A or quercetin (QUE) [35, 44, 45]. We cannot exclude the possibility that ENL will show similar properties to Schisandrin B (Sch B), an active dibenzooctadiene lignan which presents an antihyperlipidemic and hepatoprotective effects only when is supplemented for a long time in a low dosage $[46,47]$. On the other hand, when Sch B was applied in a single high dose bolus it increased serum lipid and cholesterol level in NAFLD mice [47]. Analogical effect was observed in our experiment where ENL supplementation resulted in increased fatty acid efflux from lipid overloaded hepatocytes which lipid storage capacity was exceeded and the cell was defending against lipotoxicity via increased ABCA1 and MTP expression. It is possible that in lower concentration and during prolonged exposure, similarly to Sch B, ENL will express antihyperlipidemic and hepatoprotective effects increasing lipids uptake and their further oxidation. That is why, ENL should be tested in various combinations of dose/time exposure to broadly verify its effects on lipid transporters and lipid metabolism.

\section{Conclusions}

The findings of our study demonstrate that ENL had minor and opposite effect on liver steatosis in comparison to other polyphenols which suggests that it may be an less active metabolite. ENL did not affect significantly accumulation of FFA, DAG and TAG. Furthermore, it had no influence on fatty acid transport proteins expression, yet it promoted lipids extracellular efflux. Moreover, ENL inhibited ß-oxydation and intracellular lipid metabolism via PPAR $\alpha$ what may contribute to the progression of NAFLD. Nevertheless, it selectively inhibited SREBP1c and slightly reduced PA induced inhibition of pAMPK. However, further investigations are still needed for complex verification of metabolic effects of ENL and to assess its potential usage in clinical treatment of NAFLD.

\section{Abbreviations \\ ABCA1: ATP-binding cassette transporter 1; ACBP: Acyl binding protein; ACOX: acyl-CoA oxidase; ATCC: American Type Culture Collection; BSA: Fatty acid-free bovine serum albumin; CPT 1: Carnitine palmitoyl transferase 1; DAG: Diacylglycerols; DMEM: Dulbecco Modified Eagle Medium; ECF: Extracellular fluid; ENL: Enterolactone; FABPpm: Fatty acid binding protein; FAT/CD36: Fatty acid translocase; FATP: Fatty acid transport protein; FBS: Fetal bovine serum; FFA: Free fatty acids; GAPDH: Glyceraldehyde 3-phosphate dehydrogenase; GLC: Gas liquid chromatography; HDL: High-density lipoprotein; HRP: Horseradish peroxidase; ICF: Intracellular fluid; LCFA: Long chain fatty acid; L-FABP: Liver-type fatty acid binding protein; LXR: Liver X receptor; MCFA: Medium chain fatty acid; MTP: Mitochondrial trifunctional protein; NAFLD: Non-alcoholic fatty liver disease; NASH: Non-alcoholic steatohepatitis; PA: Palmitic acid; PAMPK: phosphorylated 5' AMP-activated protein kinase; PPARa: Peroxisome proliferator-activated receptor a; QUE: Quercetin; RSV: Resveratrol; Sch B: Schisandrin B; \\ SECO: Secoisolariciresinol; SREBP1c: Sterol regulatory element-binding protein 1c; TAG: Triacylglycerols; TLC: Thin-layer chromatography; TNB: Thick needle biopsy}

\section{Acknowledgements}

We would like to thank all the technical staff of our department for the support. I confirm that I have read BioMed Central's guidance on competing interests and that none of the authors have any competing interests in the manuscript. In a name of all coauthors I agree for publication of this work in Nutrition \& Metabolism.

\section{Funding}

This work was supported by the Medical University of Bialystok grant numbers: N/ST/ZB/16/009/1118, N/ST/MN/16/001/1118 and within the National Leading Research Centre funds, grant number: 206/KNOW/16. All funding mentioned above were spent equally on reagents and materials essential for the study.

\section{Availability of data and materials}

All data generated or analyzed during this study are included in this published article [and its supplementary information files].

\section{Authors' contributions}

$K D, K K N$, AC designed the study, provided funding; $K D$ and $K B$ wrote the manuscript; $\mathrm{KD}, \mathrm{KB}$, TC and $\mathrm{NI}$ conducted experimental work; $\mathrm{B} 七$ and $\mathrm{KB}$ provided statistical analysis; KKN, Bt and AC made manuscript, and language revisions. All authors revised the paper critically for intellectual content and approved the final version.

Ethics approval and consent to participate

Not applicable

Consent for publication

Not applicable 


\section{Competing interests}

The authors declare that they have no competing interests.

\section{Publisher's Note}

Springer Nature remains neutral with regard to jurisdictional claims in published maps and institutional affiliations.

\section{Received: 29 May 2017 Accepted: 23 October 2017}

Published online: 13 November 2017

\section{References}

1. Oddy WH, Herbison CE, Jacoby P, Ambrosini GL, O'Sullivan TA, Ayonrinde OT, et al. The Western Dietary Pattern Is Prospectively Associated With Nonalcoholic Fatty Liver Disease in Adolescence.Am. J. Gastroenterol. [Internet]. 2013 [cited 2017 May 26];108:778-785. Available from: http:// www.nature.com/doifinder/10.1038/ajg.2013.95

2. Vernon G, Baranova A, Younossi ZM. Systematic review: the epidemiology and natural history of non-alcoholic fatty liver disease and non-alcoholic steatohepatitis in adults. Aliment. Pharmacol. Ther. [Internet]. 2011 [cited 2017 may 26];34:274-85. Available from: http://wuw.ncbi.nlm.nih.gov/pubmed/21623852.

3. Vos MB, Abrams Sh, Barlow Se, Caprio S, Daniels Sr, Kohli R, et al. NASPGHAN Clinical Practice Guideline for the Diagnosis and Treatment of Nonalcoholic Fatty Liver Disease in Children: Recommendations from the Expert Committee on NAFLD (ECON) and the North American Society of Pediatric Gastroenterology, Hepatology and Nutrition (NASPGHAN). J. Pediatr. Gastroenterol. Nutr. [Internet]. 2017 [cited 2017 May 26];64:319-334. Available from: http://insights.ovid.com/crossref?an=00005176-201702000-00028

4. Sanyal AJ. Mechanisms of Disease: pathogenesis of nonalcoholic fatty liver disease. Nat. Clin. Pract. Gastroenterol. Hepatol. [Internet]. 2005 [cited 2017 may 26];2:46-53. Available from: http://www.ncbi.nlm.nih.gov/pubmed/ 16265100

5. Leclercq IA, Da Silva Morais A, Schroyen B, Van Hul N, Geerts A. Insulin resistance in hepatocytes and sinusoidal liver cells: Mechanisms and consequences. J. Hepatol. [Internet]. 2007 [cited 2017 may 26];47:142-156. Available from: http://www.ncbi.nlm.nih.gov/pubmed/17512085.

6. Glatz JFC, Luiken JJFP, Bonen A. Membrane Fatty Acid Transporters as Regulators of Lipid Metabolism: Implications for Metabolic Disease. Physiol. Rev. [Internet]. 2010 [cited 2017 may 26];90:367-417. Available from: http:// www.ncbi.nlm.nih.gov/pubmed/20086080.

7. Krammer J, Digel M, Ehehalt F, Stremmel W, Füllekrug J, Ehehalt R. Overexpression of CD36 and acyl-CoA synthetases FATP2, FATP4 and ACSL1 increases fatty acid uptake in human hepatoma cells. Int. J. Med. Sci. [Internet]. 2011 [cited 2017 may 26];8:599-614. Available from: http://www. ncbi.nlm.nih.gov/pubmed/22022213.

8. Chen X, lqbal N, Boden $\mathrm{G}$. The effects of free fatty acids on gluconeogenesis and glycogenolysis in normal subjects. J. Clin. Invest. [Internet]. American Society for Clinical Investigation; 1999 [cited 2017 may 26];103:365-372. Available from: http://www.ncbi.n/m.nih.gov/pubmed/9927497.

9. Michelotti GA, Machado M V., Diehl AM. NAFLD, NASH and liver cancer. Nat. Rev. Gastroenterol Hepatol. [Internet]. 2013 [cited 2017 May 26];10:656-665. Available from: http://www.nature.com/doifinder/10.1038/nrgastro.2013.183

10. Charytoniuk T, Drygalski K, Konstantynowicz-Nowicka K, Berk K, Chabowski A.Alternative treatment methods attenuate the development of NAFLD: A review of resveratrol molecular mechanisms and clinical trials. Nutrition [Internet]. 2017 [cited 2017 May 26];34:108-117. Available from: http://www. sciencedirect.com/science/article/pii/S0899900716302076

11. Zhou F, Furuhashi K, Son MJ, Toyozaki M, Yoshizawa F, Miura Y, et al. Antidiabetic effect of enterolactone in cultured muscle cells and in type 2 diabetic model db/db mice. Cytotechnology [Internet]. 2016 [cited 2017 May 26]; Available from: http://www.ncbi.nlm.nih.gov/pubmed/27000262.

12. Chikara S, Lindsey K, Borowicz P, Christofidou-Solomidou M, Reindl KM. Enterolactone alters FAK-Src signaling and suppresses migration and invasion of lung cancer cell lines. BMC Complement Altern. Med. [Internet]. BioMed Central; 2017 [cited 2017 may 26];17:30. Available from: http://www. ncbi.nlm.nih.gov/pubmed/28068967.

13. Thompson LU, Boucher BA, Liu Z, Cotterchio M, Kreiger N. Phytoestrogen Content of Foods Consumed in Canada, Including Isoflavones, Lignans, and Coumestan. Nutr. Cancer [Internet]. 2006 [cited 2017 may 26];54:184-201. Available from: http://www.ncbi.nlm.nih.gov/pubmed/16898863.
14. Adlercreutz H. Lignans and Human Health. Crit. Rev. Clin. Lab. Sci. [Internet]. 2007 [cited 2017 may 26];44:483-525. Available from: http://www.ncbi.nlm. nih.gov/pubmed/17943494.

15. Hu C, Yuan Y V., Kitts DD. Antioxidant activities of the flaxseed lignan secoisolariciresinol diglucoside, its aglycone secoisolariciresinol and the mammalian lignans enterodiol and enterolactone in vitro. Food Chem. Toxicol. [Internet]. 2007 [cited 2017 may 26];45:2219-2227. Available from: http://www.ncbi.nlm.nih.gov/pubmed/17624649.

16. Annika I. Smeds, Patrik C. Eklund, Rainer E. Sjöholm, Stefan M. Willför, Sansei Nishibe, Takeshi Deyama and, et al. Quantification of a Broad Spectrum of Lignans in Cereals, Oilseeds, and Nuts. American Chemical Society; 2007 [cited 2017 May 26]; Available from: http://pubs.acs.org/doi/abs/10.1021/ jf0629134

17. Konstantynowicz-Nowicka K, Harasim E, Baranowski M, Chabowski A. New Evidence for the Role of Ceramide in the Development of Hepatic Insulin Resistance. Cowart A, editor. PLoS One [Internet]. 2015 [cited 2017 may 26];10: e0116858. Available from: http://www.ncbi.n/m.nih.gov/pubmed/25635851.

18. FOLCH J, LEES M, SLOANE STANLEY GH. A simple method for the isolation and purification of total lipides from animal tissues. J. Biol. Chem. [Internet]. 1957 [cited 2017 may 26];226:497-509. Available from: http://www.ncbi.nlm. nih.gov/pubmed/13428781.

19. van der Vusse GJ, Roemen TH, Reneman RS. Assessment of fatty acids in dog left ventricular myocardium. Biochim. Biophys. Acta [Internet]. 1980 [cited 2017 may 26];617:347-349. Available from: http://www.ncbi.nlm.nih. gov/pubmed/7357024.

20. Sanyal AJ, Friedman SL, McCullough AJ, Dimick-Santos L, American Association for the Study of Liver Diseases, United States Food and Drug Administration. Challenges and opportunities in drug and biomarker development for nonalcoholic steatohepatitis: Findings and recommendations from an American Association for the Study of Liver Diseases-U.S. Food and Drug Administration Joint Workshop. Hepatology [Internet]. 2015 [cited 2017 May 26];61:1392-405. Available from: http:// www.ncbi.nlm.nih.gov/pubmed/25557690

21. Clavel T, Doré J, Blaut M. Bioavailability of lignans in human subjects. Nutrition Research Reviews. 200619 (02) pp: 187-196.

22. Bolvig A, Kyrø C, Nørskov N, Eriksen A, Christensen J, Tjønneland A, et al. Use of antibiotics is associated with lower enterolactone plasma concentration. Molecular Nutri Food Res. 2016;60(12):2712-21.

23. Ehehalt R, Füllekrug J, Pohl J, Ring A, Herrmann T, Stremmel W. Translocation of long chain fatty acids across the plasma membrane - lipid rafts and fatty acid transport proteins. Mol. Cell. Biochem. [Internet]. 2006 [cited 2017 may 26];284:135-40. Available from: http://www.ncbi.nlm.nih. gov/pubmed/16477381.

24. Kitts DD, Yuan Y V, Wijewickreme AN, Thompson LU. Antioxidant activity of the flaxseed lignan secoisolariciresinol diglycoside and its mammalian lignan metabolites enterodiol and enterolactone. Mol. Cell. Biochem. [Internet]. 1999 [cited 2017 may 26];202:91-100. Available from: http://www. ncbi.nlm.nih.gov/pubmed/10705999.

25. McIntosh AL, Atshaves BP, Landrock D, Landrock KK, Martin GG, Storey SM et al. Liver fatty acid binding protein gene-ablation exacerbates weight gain in high-fat fed female mice. Lipids [Internet]. NIH Public Access; 2013 [cited 2017 may 26];48:435-48. Available from: http://www.ncbi.nlm.nih.gov/ pubmed/23539345.

26. Holmes RS, S. R. Comparative Studies of Vertebrate Platelet Glycoprotein 4 (CD36). Biomolecules [Internet]. Molecular Diversity Preserv Int; 2012 [cited 2017 May 26];2:389-414. Available from: http://www.mdpi.com/2218-273X/2/3/389/

27. Kersten S. Integrated physiology and systems biology of PPARa. Mol. Metab. [Internet]. 2014 [cited 2017 may 26];3:354-71. Available from: http://www. ncbi.nlm.nih.gov/pubmed/24944896.

28. Wang G, Bonkovsky HL, de Lemos A, Burczynski FJ. Recent insights into the biological functions of liver fatty acid binding protein 1. J. Lipid Res. [Internet]. 2015 [cited 2017 may 26];56:2238-2247. Available from: http:// www.ncbi.nlm.nih.gov/pubmed/26443794.

29. Harasim-Symbor E, Konstantynowicz-Nowicka K, Chabowski A. Additive effects of dexamethasone and palmitate on hepatic lipid accumulation and secretion. J. Mol. Endocrinol. [Internet]. 2016 [cited 2017 may 26];57:261-73. Available from: http://www.ncbi.nlm.nih.gov/pubmed/27707773.

30. Yancey PG, Bortnick AE, Kellner-Weibel G, de la Llera-Moya M, Phillips MC, Rothblat GH. Importance of Different Pathways of Cellular Cholesterol Efflux. Arterioscler. Thromb. Vasc. Biol. [Internet]. 2003 [cited 2017 may 26];23:712719. Available from: http://www.ncbi.n/m.nih.gov/pubmed/12615688. 
31. Iqbal J, Parks JS, Hussain MM. Lipid absorption defects in intestine-specific microsomal triglyceride transfer protein and ATP-binding cassette transporter A1-deficient mice. J. Biol. Chem. [Internet]. American Society for Biochemistry and Molecular Biology; 2013 [cited 2017 may 26];288:3043244. Available from: http://www.ncbi.nlm.nih.gov/pubmed/24019513.

32. Tominaga S, Nishi K, Nishimoto S, Akiyama K, Yamauchi S, Sugahara T. (-)-Secoisolariciresinol attenuates high-fat diet-induced obesity in C57BL/6 mice. Food Funct. [Internet]. 2012 [cited 2017 may 26];3:76-82. Available from: http://www.ncbi.nlm.nih.gov/pubmed/22030618.

33. Huang C-Z, Tung Y-T, Hsia S-M, Wu C-H, Yen G-C. The hepatoprotective effect of Phyllanthus emblica $L$. fruit on high fat diet-induced non-alcoholic fatty liver disease (NAFLD) in SD rats. Food Funct. [Internet]. 2017 [cited 2017 may 26];8:842-50. Available from: http://www.ncbi.nlm.nih.gov/ pubmed/28128372.

34. Moon Y-A, Hammer RE, Horton JD. Deletion of ELOVL5 leads to fatty liver through activation of SREBP-1C in mice. J. Lipid Res. [Internet]. American Society for Biochemistry and Molecular Biology; 2009 [cited 2017 may 26]; 50:412-423. Available from: http://www.ncbi.nlm.nih.gov/pubmed/ 18838740 .

35. Consitt LA, Bell JA, Houmard JA. Intramuscular lipid metabolism, insulin action, and obesity. IUBMB Life. NIH Public Access; 2009 [cited 2017 may 26];61:47-55. Available from: http://www.ncbi.nlm.nih.gov/pubmed/18839419.

36. Winder WW, Hardie DG. AMP-activated protein kinase, a metabolic master switch: possible roles in type 2 diabetes. Am. J. Physiol. [Internet]. 1999 [cited 2017 may 26];277:E1-10. Available from: http://www.ncbi.nlm.nih.gov/ pubmed/10409121.

37. Lu K-L, Xu W-N, Wang L-N, Zhang D-D, Zhang C-N, Liu W-B. Hepatic $\beta$ Oxidation and Regulation of Carnitine Palmitoyltransferase (CPT) I in Blunt Snout Bream Megalobrama amblycephala Fed a High Fat Diet. Zhang Y, editor. PLoS One [Internet]. 2014 [cited 2017 may 26];9:e93135. Available from: http://www.ncbi.nlm.nih.gov/pubmed/24676148.

38. Kohjima M, Enjoji M, Higuchi N, Kato M, Kotoh K, Yoshimoto T, et al. Reevaluation of fatty acid metabolism-related gene expression in nonalcoholic fatty liver disease. Int. J. Mol. Med. [Internet]. 2007 [cited 2017 may 26];20: 351-8. Available from: http://www.ncbi.nlm.nih.gov/pubmed/17671740.

39. Monsalve FA, Pyarasani RD, Delgado-Lopez F, Moore-Carrasco R. Peroxisome Proliferator-Activated Receptor Targets for the Treatment of Metabolic Diseases. Mediators Inflamm. [Internet]. 2013 [cited 2017 may 26];2013:1-18. Available from: http://www.ncbi.nlm.nih.gov/pubmed/23781121.

40. Souza-Mello V, Gregório BM, Cardoso-de-Lemos FS, de Carvalho L, Aguila MB, Mandarim-de-Lacerda CA. Comparative effects of telmisartan, sitagliptin and metformin alone or in combination on obesity, insulin resistance, and liver and pancreas remodelling in C57BL/6 mice fed on a very high-fat diet. Clin. Sci. [Internet]. 2010 [cited 2017 may 26];119:239-50. Available from: http://www.ncbi.nlm.nih.gov/pubmed/20415664.

41. Schultz A, Neil D, Aguila M, Mandarim-de-Lacerda C. Hepatic Adverse Effects of Fructose Consumption Independent of Overweight/Obesity. Int. J. Mol. Sci. [Internet]. 2013 [cited 2017 may 26];14:21873-86. Available from: http:// www.ncbi.nlm.nih.gov/pubmed/24196354.

42. Pan A, Sun J, Chen Y, Ye X Li H, Yu Z, et al. Effects of a flaxseed-derived lignan supplement in type 2 diabetic patients: a randomized, double-blind, cross-over trial. PLoS One [Internet]. Public Library of Science; 2007 [cited 2017 may 26];2:e1148. Available from: http://www.ncbi.nlm.nih.gov/ pubmed/17987126.

43. Higuchi N, Kato M, Shundo Y, Tajiri H, Tanaka M, Yamashita N, et al. Liver X receptor in cooperation with SREBP-1C is a major lipid synthesis regulator in nonalcoholic fatty liver disease. Hepatol. Res. [Internet]. 2008 [cited 2017 may 26];38:1122-9. Available from: http://www.ncbi.nlm.nih.gov/pubmed/ 18684130.

44. Zhu M, Harshbarger WD, Robles O, Krysiak J, Hull KG, Cho SW, et al. A strategy for dual inhibition of the proteasome and fatty acid synthase with belactosin C-orlistat hybrids. Bioorg. Med. Chem. [Internet]. 2017 [cited 2017 may 26];25:2901-16. Available from: http://www.ncbi.nlm.nih.gov/pubmed/ 28236510.

45. Porras D, Nistal E, Martínez-Flórez S, Pisonero-Vaquero S, Olcoz JL, Jover R, et al. Protective effect of quercetin on high-fat diet-induced non-alcoholic fatty liver disease in mice is mediated by modulating intestinal microbiota imbalance and related gut-liver axis activation. Free Radic. Biol. Med. [Internet]. 2017 [cited 2017 may 26];102:188-202. Available from: http:// www.ncbi.nlm.nih.gov/pubmed/27890642.
46. Leong PK, Ko KM. Schisandrin B: A Double-Edged Sword in Nonalcoholic Fatty Liver Disease. Oxid. Med. Cell. Longev. [Internet]. Hindawi Publishing Corporation; 2016 [cited 2017 May 26];2016:1-13. Available from: https:// www.hindawi.com/journals/omcl/2016/6171658/

47. Pan S-Y, Dong H, Guo B, Zhang Y, Yu Z-L, Fong W-F, et al. Effective kinetics of schisandrin $B$ on serum/hepatic triglyceride and total cholesterol levels in mice with and without the influence of fenofibrate. Naunyn. Schmiedebergs. Arch. Pharmacol. [Internet]. 2011 [cited 2017 may 26];383: 585-91. Available from: http://www.ncbi.nlm.nih.gov/pubmed/21523558.

\section{Submit your next manuscript to BioMed Central and we will help you at every step:}

- We accept pre-submission inquiries

- Our selector tool helps you to find the most relevant journal

- We provide round the clock customer support

- Convenient online submission

- Thorough peer review

- Inclusion in PubMed and all major indexing services

- Maximum visibility for your research

Submit your manuscript at www.biomedcentral.com/submit
C Biomed Central 